Jurnal Widya Laksana, Vol.10, No.2, Agustus 2021

\title{
IbM PELATIHAN PENGELOLAAN SARANA DAN LINGKUNGAN SEKOLAH DASAR BERBASIS LITERASI DI DESA BAKTISERAGA
}

\author{
I Nengah Martha ${ }^{1}$, Ade Asih Susiari Tantri ${ }^{2}$, I Putu Mas Dewantara ${ }^{3}$, Made Sri \\ Indriani ${ }^{4}$, Gede Wira Bayu ${ }^{5}$ \\ ${ }^{1234}$ Jurusan Bahasa, Sastra Indonesia, dan Daerah, Universitas Pendidikan Ganesha \\ 5Jurusan Pendidikan Dasar, Universitas Pendidikan Ganesha \\ e-mail: nengah.martha@undiksha.ac.id, susiari.tantri@undiksha.ac.id, \\ mas.dewantara@undiksha.ac.id,sri.indriyani@undiksha.ac.id, \\ wira.bayu@undiksha.ac.id
}

\begin{abstract}
Abstrak
Kegiatan PkM ini dilakukan di SD Negeri 1 Baktisegara, Kecamatan Buleleng, Kabupaten Buleleng, Bali. Mitra ini dipilih karena memiliki masalah, yaitu kemampuan pengelolaan sarana dan lingkungan sekolah yang belum berbasis literasi. Mengingat begitu pentingnya Gerakan Literasi Sekolah, salah satunya adalah mengelola sarana dan lingkungan sekolah yang kaya teks, maka kegiatan PkM berkaitan dengan pelatihan pengelolaan sarana dan lingkungan sekolah dasar berbasis literasi perlu dilakukan. Tujuannya adalah SD Negeri 1 Baktiseraga secara mandiri nantinya mampu mengelola dan mengembangkan sarana dan lingkungan yang kaya teks dan tujuan berikutnya siswa semakin meningkatnya semangat belajar dan minat baca siswa. Metode pelaksanaan kegiatan PkM ini akan dilakukan melalui beberapa tahapan, yaitu: 1) pelatihan pengelolaan sarana dan lingkungan sekolah berbasis literasi; 2) pendampingan pengelolaan sarana dan lingkungan sekolah berbasis literasi; dan 3) evaluasi dan refleksi kegiatan PkM. Hasil dari kegiatan pengabdian ini adalah kepala SD N 1 Baktiseraga dan guru sangat antusias mengikuti kegiatan ini. Saat diskusi guru sangat antusias bertanya terkait program yang dibuat. Setelah dilakukan kegiatan workshop, guru kemudian membuat program menata sarana dan lingkungan yang kaya literasi. Kegiatan ini didampingi secara online oleh para pengabdi.
\end{abstract}

Kata kunci: Sarana dan Lingkungan, Sekolah Dasar, Berbasis Literasi

\begin{abstract}
This PkM activity was carried out at SD Negeri 1 Baktisegara, Buleleng District, Buleleng Regency, Bali. This partner was chosen because he had problems, namely the ability to manage facilities and school environments that were not literacy-based. Given the importance of the School Literacy Movement, one of which is managing text-rich school facilities and environments, PkM activities related to literacy-based primary school facilities and environment management training need to be carried out. The goal is that SD Negeri 1
\end{abstract}


Baktiseraga will be able to independently manage and develop text-rich facilities and environments and the next goal for students is to increase their enthusiasm for learning and reading interest. The method of implementing this PkM activity will be carried out in several stages, namely: 1) literacy-based training in the management of school facilities and environment; 2) assistance in the management of school facilities and environment based on literacy; and 3 ) evaluation and reflection of PkM activities. The result of this service activity was that the principal of SD N 1 Baktiseraga and teachers were very enthusiastic about participating in this activity. During the discussion, the teacher was very enthusiastic about asking questions related to the program being made. After the workshop activities are carried out, the teacher then makes a program to organize the facilities and environment that is rich in literacy. This activity was accompanied online by the servants.

Keywords: Facilities and Environment, Elementary School, Literacy Based

\section{PENDAHULUAN}

Gerakan literasi sekolah (GLS) merupakan gerakan wajib Kemendikbud di Sekolah Dasar, Sekolah Menengah Pertama, dan Sekolah Menengah Atas yang bertujuan untuk meningkatkan minat baca dan menjadikan generasi muda Indonesia yang literat. Sesuai pengertian di atas, GLS adalah "sebuah upaya yang dilakukan secara menyeluruh untuk menjadikan sekolah sebagai organisasi pembelajaran yang warganya literat sepanjang hayat melalui pelibatan publik" (Kemendikbud, 2016). Secara khusus, menurut Suragangga (Batubara \& Ariani, 2018), salah satu tujuan GLS adalah sekolah menjadikan sekolah sebagai lingkungan yang nyaman dan ramah bagi siswa untuk belajar. Tujuan khusus ini tercermin dari salah satu langkah dalam pelaksanaan program GLS, yaitu menata sarana dan lingkungan sekolah kaya literasi.

Menata sarana dan lingkungan sekolah kaya literasi bertujuan untuk menumbuhkan rasa nyaman belajar dan menumbuhkan motivasi siswa untuk gemar membaca. Sarana literasi misalnya perpustakaan, sudut baca kelas, area baca, UKS, kantin sekolah, dan kebun sekolah. Menurut hasil penelitian Alfi (2010) dalam junal "UI Untuk Bangsa Seri Sosial dan Humaniora" yang berjudul "Optimalisasi Budaya Literasi di Kalangan Mahasiswa: Upaya Meretas Komunikasi Global' cara yang bisa dilakukan untuk mengoptimalkan budaya literasi, salah satunya adalah optimalisasi fungsi perpustakaan.

Selain sarana, lingkungan sekolah yang kaya literasi perlu dikelola dengan baik misalnya memajang karya tangan siswa seperti slogan, poster, lukisan, gambar, grafik, dan kerajinan tangan lainnya di setiap sudut sekolah. Hal ini dapat menumbuhkan rasa percaya diri siswa dan memotivasi siswa untuk semakin kreatif serta belajar lebih giat lagi. Maka dari itu, mengelola sarana dan lingkungan sekolah kaya literasi sangat penting dilakukan. Hal ini didukung oleh pendapat mengenai salah satu strategi penting dalam pelaksanaan GLS (Teguh, 2013).

Terkait dengan hal di atas, berdasarkan hasil observasi awal 
masih banyak lingkungan sekolah dasar di desa Banjar belum dikelola dengan baik. Keadaan lingkungan sekolah sudah bersih dan nyaman, namun tidak kaya literasi. Padahal dalam panduan GLS sudah dijelaskan bahwa salah satu langkah penting yang harus dilakukan adalah mengelola sarana dan lingkungan sekolah yang kaya literasi. Masalah yang dialami oleh dua sekolah ini juga ternyata berlaku secara nasional. Menurut Huda (dalam Hidayat, Basuki, \& Akbar, 2018), bahwa ada 3 masalah yang dihadapi oleh pihak sekolah saat melaksanakan program GLS, yaitu "kurang tersedianya tempat membaca, seperti perpustakaan, sudut baca, dan sebagainya yang mendukung pelaksanaan kegiatan GLS”.

Terkait hal di atas, PkM ini dilaksanakan di SD 1 Baktiseraga, Kecamatan Buleleng, Kabupaten Buleleng, Provinsi Bali. Berdasarkan hasil observasi awal, SD Negeri 1 Baktiseraga bisa dikatakan memiliki lingkungan yang bersih. Namun, lingkungan yang bersih ini belum mencerminkan lingkungan yang kaya literasi. Hal ini bisa dilihat dari halaman sekolah, ruang kelas, ruang UKS, kantin, dan perpustakaan. Sebenarnya untuk menciptakan lingkungan sekolah yang kaya literasi tidak harus mengelurkan dana, sarana, dan prasaran yang banyak. Pihak sekolah bisa memajang hasil kerajinan siswa. Sekolah juga bisa memajang slogan dan poster hasil tangan siswa. Selain itu, pihak sekolah juga bisa memanfaatkan barang-barang bekas untuk menjadikan lingkungan sekolah kaya literasi, misalnya membuat pojok baca, pohon ilmu dan membuat apotek hidup di kebun sekolah.

Terkait dengan permasalahan di atas, maka pengabdian kepada masyarakat terkait dengan pengelolaan sarana dan lingkungan sekolah berbasis literasi ini perlu dilakukan. Sekolah sebagai ujung tombak kemajuan bangsa dan sebagai tempat belajar bagi siswa harus dikelola dengan baik dan dapat memotivasi siswa untuk giat membaca. Maka dari itu, melalui kegiatan pengandian kepada masyarakat ini diharapkan warga sekolah terutama kepala sekolah sebagai pengambil kebijakan dan guru sebagai fasilitator dan motivator bagi siswa, memiliki pemahaman mengenai cara mengelola lingkungan sekolah yang kaya dengan literasi. Dampak lainnya adalah siswa menjadi semakin tertarik dan semangat untuk belajar serta motivasi siswa untuk membaca semakin meningkat.

Dari hasil observasi awal dan wawancara dengan kepala sekolah serta guru di SD Negeri 1 Baktiseraga, ada beberapa masalah yang dihadapi terkait dengan pengelolaan sarana dan lingkungan yang kaya teks. Pertama, sarana dan prasarana yang tidak mendukung. Kedua, tidak paham cara mengelola sarana dan lingkungan agar kaya teks. Ketiga, karya tangan siswa yang bagus dan baik tidak dipajang, tetapi dikembalikan kepada siswa. Keempat, buku yang ada di perpustakaan sangat minim, terutama buku bacaan dan buku cerita. Kelima, tidak paham cara memanfaatkan barang-barang bekas untuk menciptakan lingkungan sekolah kaya teks. Keenam jumlah siswa yang berkunjung ke perpustakaan sangat 
sedikit. Ketujuh, minat baca siswa rendah.

Berdasarkan identifikasi masalah yang dihadapi oleh mitra di atas, maka prioritas masalah yang akan ditangani dalam kegiatan PkM ini adalah apakah terdapat peningkatan pemahaman guru terhadap pengelolaan lingkungan sekolah berbasis literasi? dan bagaimanakah respon guru terhadap lingkungan sekolah berbasis literasi dari hasil pelatihan?

\section{METODE}

PkM ini menggunakan metode pendekatan pemberdayaan dengan prinsip partisipasi aktif dari kepala sekolah sebagai pengampu kebijakan dan guru yang ada di SD Negeri 1 Baktiseraga. Tim pelaksana PkM bertugas sebagai narasumber, pelatih, dan pendamping dalam mengelola lingkungan sekolah berbasis literasi. Metode pelaksanaan kegiatan ini terdiri dari beberapa tahap, yaitu sebagai berikut.

1. Memberikan pemahaman dan pelatihan melalui kegiatan workshop mengenai pentingnya dan cara mengelola dan mengembangkan sarana dan lingkungan sekolah berbasis literasi.

2. Memberikan pendampingan agar pengelolaan sarana dan lingkungan sekolah berbasis literasi yang sudah dicanangkan oleh sekolah saat workshop dapat berjalan dengan baik dan berkembang menjadi perpustakaan yang semakin berkualitas. Sekolah yang didampingi, yaitu SD Negeri 1 Baktiseraga.
3. Melakukan evaluasi dan refleksi melalui kegiatan FGD (Fokus Group Discussion) melalui google meet antara tim pelaksana dengan kepala sekolah dan guru SD Negeri 1 Baktiseraga.

\section{HASIL DAN PEMBAHASAN}

Hasil

\section{Kegiatan Awal}

Pada awalnya, kegiatan ini akan dilakukan di SD N 3 Sambangan, namun karena adanya musibah covid 19 dari April 2020 sampai sekarang, pihak kepala sekolah tidak bisa membantu tim pengabdian untuk melaksakannya. Kemudian, akhirnya dengan masalah yang hampir sama, yaitu lingkungan sekolah belum dikelola dengan baik. Artinya belum mecerminkan lingkungan yang kaya literasi, maka kepala sekolah SD N 1 Baktiseraga berkenan untuk memberi izin melaksanakan pengabdian. Pengabdian dilaksanakan setelah libur Hari Raya Galungan dan Kuningan. Pengabdian ini dilakukan secara virtual atau daring dengan mengundang semua guru di SD N 1 Baktiseraga. Pengabdian dilaksanakan setelah libur Hari Raya Galungan dan Kuningan. Pengabdian ini dilakukan secara virtual atau daring dengan mengundang semua guru di SD N 1 Baktiseraga.

\section{Workshop Pelatihan Menyusun Program Lingkungan Sekolah yang Kaya Literasi}

Setelah mendapatkan izin dari kepala SD N 1 Baktiseraga, kegiatan pelatihan yang dikemas dalam bentuk workshop ini dilaksanakan tanggal 4 Oktober 2020 pukul 09.00 WITA secara daring melalui google meet dengan link 
meet.google.com/hpb-kgah-rys.

Kegiatan ini diikuti oleh kepala sekolah dan guru-guru SD N 1 Baktiseraga.

Kegiatan dibuka oleh kepala SD

N 1 Baktiseraga. Kepala sekolah menyampaikan bahwa kegiatan pengandian ini sangat penting dilakukan mengigat sekolah SD N 1 Baktiseraga hanya melakukan kegiatan literasi di tahap membaca 15 menit sebelum jam pelajaran. Kepala sekolah juga menekankan kepada guru-guru yang mengikuti kegiatan ini untuk semangat mengikuti kegiatan dan mengaplikasi materi yang yang diberikan oleh narasumber dengan baik. Tujuannya agar sekolah SD N 1 Baktiseraga dapat menata lingkungan sekolah yang kaya literasi. Berikut adalah foto saat kepala SD N 1 Baktiseraga membuka acara workshop.

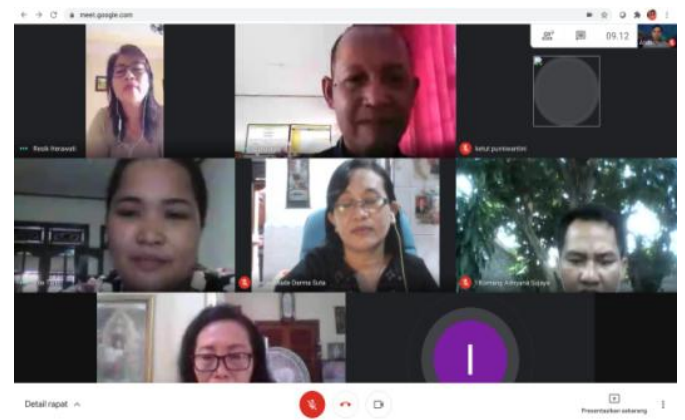

Gambar 1. Kepala SD N 1 Baktisegara Membuka Acara Workshop

Setelah dibuka oleh kepala SD N 1 Baktiseraga, ketua pengabdi memberikan kata pengatar terkait pentingnya kegiatan ini dilakukan. Ketua pengabdi juga memberikan kesempatan kepada para guru untuk berdiskusi di luar kegiatan ini, jikalau ada kendala-kendala yang dihadapi saat merealisasikan program yang telah dibuat. $\begin{array}{cll}\begin{array}{c}\text { Setelah } \\ \text { memberikan }\end{array} & \text { ketua } & \text { pengabdi } \\ \text { kata } & \text { pengatar, }\end{array}$ narasumber kemudian menjelaskan mengenai cara menata lingkungan sekolah yang kaya literasi selama kurang lebih 30 menit. Narasumber dalam kegiatan ini adalah salah satu anggota pengabdi yang bidangnya di keterampilan membaca. Narasumber pernah melakukan penelitian dan pengabdian di bidang literasi yang dilaksanakan di sekolah dasar. Narasumber juga pernah mengampu mata kuliah membaca pemahaman

Setelah narasumber memberikan materi, kegiatan berikutnya adalah kegiatan diskusi. Kegiatan diskusi ini dipandu oleh moderator. Moderator dalam kegiatan ini adalah salah satu anggota pengabdi. Peserta sangat antusias bertanya terkait dengan cara menata lingkungan yang kaya literasi. Pertanyaan yang muncul, yaitu: 1) bagaimana cara membuat pojok baca di kelas, kalua kelas sempit karena jumlah siswa yang terlalu banyak?; 2) bagaimana cara meningkatkan semangat siswa untuk melakukan kegiatan lietrasi saat pembelajaran daring?; 3) bagaimana cara menentukan karya siswa yang akan dipajang di ruang kelas?; 4) bagaimana cara mengajak siswa untuk menata ruangan kelas yang kaya literasi; 5) bagaimana cara memotivasi guru agar semangat untuk menyukseskan kegiatan literasi, khususnya menata lingkungan sekolah yang kaya literasi?; dan 6) bagaimana cara mengajak siswa kelas rendah, yaitu kelas satu dan dua agar mau melakukan kegiatan membaca 15 menit sebelum jam pelajaran. Satu persatu pertanyaan ini dijawab oleh narasumber dan sesekali 
anggota pengabdi lainnya memberikan masukan dan saran. Berikut foto screen shoot saat kegiatan diskusi.

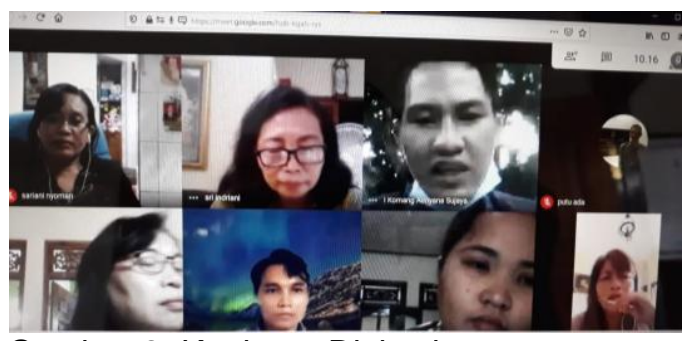

Gambar 2. Kegiatan Diskusi

Kegiatan workshop kemudian ditutup oleh ketua pengabdi. Namun sebelumnya, kepala SD N 1 Baktiseraga memnyampaikan pesan dan kesan mengenai kegiatan ini. Selain kepala SD N 1 Baktiseraga menyampaikan pesan dan kesan, peserta atau guru-guru yang ikut kegiatan ini juga menyampaikan pesan dan kesan selama mengikuti kegiatan ini.

\section{Pendampingan Pelaksanaan}

Program Pengelolaan Sarana dan Lingkungan yang Kaya Literasi Mengingat masih dilakukannya pembatasan sosial kegiatan pendampingan dilakukan secara daring. Kegiatan pendampingan ini dilakukan tanggal 13 Oktober 2020. Pendampingan hanya dilakukan sebatas pendampingan pembuatan program. Hal ini karena sekolah masih menerapkan pembelajaran secara daring. Masing-masing wali kelas membuat program untuk menata kelas yang kaya literasi. Berikut salah satu contoh program yang dibuat oleh guru.

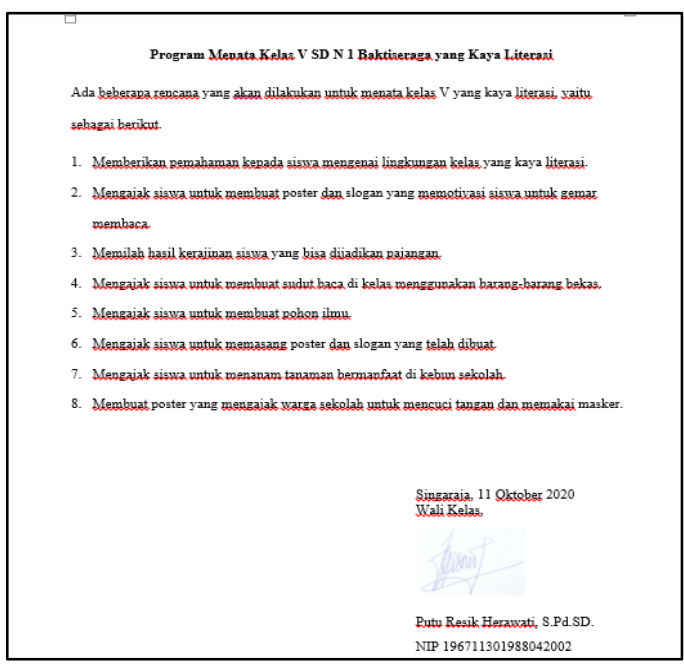

Gambar 3. Contoh Program yang Dibuat oleh Guru

Program yang dibuat oleh guru ini dan kemudian diberikan masukan oleh anggota pengabdi. Guru sangat antusias bertanya jawab untuk menyempurnakan program yang dibuat. Pogram ini rencananya akan dilaksanakan setelah kondisi kembali normal atau setelah kegiatan pembelajaran tatap muka dilakukan.

\section{Pembahasan}

Kegiatan PkM ini memang penting dilaksanakan. Masih banyak sekolah-sekolah yang belum memahami tentang program wajib Kemendikbud untuk mingkatkan angka minat baca siswa melalui kegiatan GLS (Gerakan Literasi Sekolah). "GLS adalah kemampuan mengakses, memahami, dan menggunakan sesuatu secara cerdas melalui berbagai aktivitas, antara lain membaca, melihat, menyimak, menulis, dan/atau berbicara" (Faizah, dkk, 2016:2).

Begitu juga halnya di SD N 1 Baktiseraga. $\mathrm{Di}$ SD ini telah menerapkan GLS, namun baru sebatas 
membaca 15 menit sebelum jam pelajaran dimulai. Pihak kepala sekolah dan guru tidak memahami bahwa menata lingkungan yang kaya literasi adalah satu bagian dari program GLS.

Berkaitan dengan hal di atas, kepala SD N 1 Baktiseraga dan guru sangat antusias mengikuti kegiatan ini. Saat diskusi guru sangat antusias bertanya terkait program yang dibuat. Setelah dilakukan kegiatan workshop, guru kemudian membuat

Berkaitan dengan hal di atas, kepala SD N 1 Baktiseraga dan guru sangat antusias mengikuti kegiatan ini. Saat diskusi guru sangat antusias bertanya terkait program yang dibuat. Setelah dilakukan kegiatan workshop, guru kemudian membuat program menata sarana dan lingkungan yang kaya literasi. Kegiatan ini didampingi secara online oleh para pengabdi.

Usaha yang dilakukan oleh sekolah ini sudah cukup bagus. Dengan menerapkan 15 menit membaca sebelum jam pelajaran, ini berarti pihak sekolah sudah mewujudkan program wajib Kemendikbud untuk meningkatkan minat baca masyarakat Indonesia, khususnya siswa. Komitmen sekolah untuk mengembangkan program menata sarana dan lingkungan yang kaya literasi ini adalah langkah yang tepat dan bijak untuk mewujudkan masyarakat Indonesia yang literat seperti yang diimpi-impikan bangsa Indonesia.

\section{KESIMPULAN}

Berdasarkan hasil yang dicapai dapat disimpulkan bahwa kegiatan P2M ini memang penting dilaksanakan. Masih banyak sekolah-sekolah yang belum memahami tentang program wajib Kemendikbud untuk mingkatkan angka minat baca siswa melalui kegiatan GLS (Gerakan Literasi Sekolah). Berkaitan dengan hal ini, guru sangat antusias mengikuti kegiatan ini. Saat diskusi guru sangat antusias bertanya terkait program yang dibuat. Setelah dilakukan kegiatan workshop, guru kemudian membuat program menata sarana dan lingkungan yang kaya literasi. Kegiatan ini didampingi secara daring oleh para pengabdi.

\section{DAFTAR PUSTAKA}

Alfi, S. 2010. Optimalisasi Budaya Literasi di Kalangan Mahasiswa: Upaya Meretas Komunikasi Global. Jurnal UI Untuk Bangsa Seri Sosial dan Humaniora. Volume 1, Desember 2010, 67-78.

Batubara, H. H., \& Ariani, D. N. (2018). Implementasi Program Gerakan Literasi Sekolah di Sekolah Dasar Negeri Gugus Sungai Miai Banjarmasin. Jurnal Pendidikan Sekolah Dasar, 4(1), 15. https://doi.org/10.30870/jpsd.v4i1. 2965.

Faizah, Dewi Utama, dkk. 2016. Panduan Gerakan Literasi Sekolah di Sekolah Dasar. Jakarta:Direktorat Pembinaan Sekolah Dasar.

Hidayat, M. H., Basuki, I. A., \& Akbar, S. (2018). Gerakan literasi Sekolah Dasar. Pendidikan, 3(6), 810-817. Retrieved from http://journal.um.ac.id/index.php/jp tpp/article/view/11213.

Kemendikbud. (2016). Panduan Gerakan Literasi Sekolah di Sekolah Dasar. (P. . P. Pangesti 
Jurnal Widya Laksana, Vol.10, No.2, Agustus 2021

Wiedarti, M.Appl.Ling. \& D. Kisyani-Laksono, Eds.), Direktorat Pembinaan Sekolah Dasar Direktorat Jenderal Pendidikan Dasar dan Menengah Kementerian Pendidikan dan Kebudayaan. Jakarta. Retrieved from

http://repositori.perpustakaan.kem
dikbud.go.id/40/1/PanduanGerakan-Literasi-Sekolah-diSD.pdf.

Teguh, M. (2013). Gerakan Literasi Sekolah Dasar (pp. 18-26). Retrieved from http://pgsd.umk.ac.id/files/prosidin g/2017/3 Mulyo Teguh.pdf 